\title{
LA CULTURA VOCACIONAL EN LA IGLESIA PARTICULAR
}

DOI: https://doi.org/10.52039/seminarios.v62i218.108

MiLTON LUIS TRÓcColi CeBeido*

Antes de hablar de la cultura vocacional, conviene que dirijamos nuestra mirada a la cultura actual y nos interroguemos por sus novedades y características, especialmente de la cultura juvenil.

\section{LA CULTURA DE HOY NOS DESAFía. UNA IGLESIA EN SALIDA ${ }^{1}$}

Para muchos vivir se ha vuelto una tarea difícil. Engendrar vida, hacerla viable, comer, crecer, curarse, vincularse, enseñar y trabajar. Estas acciones básicas de una civilización, hoy no están aseguradas. Lo que en otros tiempos apenas si era objeto de la reflexión, se ha vuelto una cuestión urgente y amenazante.

La vida del cristianismo y de las iglesias se ha hecho ardua. Dar vida evangélica, alimentar con la palabra y el pan del Cristo, hacer crecer las comunidades y las personas, vivir juntos la fe y acompañar nuestro tiempo son dimensiones de la existencia cristiana que tienen a muchos seguidores de Jesús desbordados, exigidos y desorientados.

Millones de inmigrantes han clavado sus culturas y credos religiosos en el corazón de los países más ricos del mundo, e incluso en el de los que no lo son mucho. La decisión de existir juntos todavía tiene demasiadas sombras. El desorbitado poder de los grandes rompe, diaria e impunemente, vidas y pactos. Los grupos humanos buscan reconstituir su identidad a fuerza de memorias, de sufrimientos, de búsquedas y, llegado el caso, también de defensa y agresión.

Es habitual escuchar que el mundo ha cambiado en las últimas décadas. Se habla no sólo de un tiempo de cambios, sino también de un verdadero cambio de época o «cambio epocal», con todo lo que esto conlleva de mutaguay).

* Milton Luis Tróccoli Cebeido es obispo auxiliar de la diócesis de Montevideo (Uru-

1. Nos basamos para esta ponencia en el libro de A. Cencini, No cuentan los números. Construir una cultura vocacional, Paulinas, Madrid 2012, así como en las Conclusiones del II Congreso Continental Latinoamericano de Vocaciones. 
ciones profundas, de perplejidad y de inseguridad. Se afirma cada vez más que vivimos en una época «post»: post-moderna, post-industrial, post-comunista, post-guerra fría.

Asistimos a un cambio de época que nos concierne a todos y que nadie puede eludir. No sólo influye en nuestras tradicionales concepciones políticas, en nuestras frágiles estructuras socioeconómicas y en nuestra peculiar manera de relacionarnos con Dios, sino que afecta incisivamente a nuestra cultura en su totalidad.

Se trata de una "atmósfera» de época, que también suele emerger en el vocabulario que se utiliza cuando se intenta explicar lo que sucede. Tres tipos de términos aparecen. Por una parte, ha aumentado el uso de una serie de palabras compuestas con los prefijos «des» y "post» (postmoderno, desmantelamiento, desestructurar, postindustrial), que indican una conciencia de final, de cosas que han sido superadas, de la necesidad de enterrar muchas convicciones y estilos de ayer. Pero, por otra, también ha aumentado considerablemente la utilización de términos antecedidos por «re» y «neo» (refundación, recuperar, reencantamiento, neoliberalismo, nueva era), que insinúan que lo vivido en otros momentos contiene valores que no pueden ser olvidados; que el hoy ha perdido cosas con respecto al ayer y que no todo se soluciona con el salto hacia el futuro.

Los cristianos debemos acoger la dificultad y la ambigüedad del tiempo presente. Es necesario que vayamos construyendo con paciencia y con humildad nuevas instancias de reflexión y de práctica, sin caer en determinismos ni en voluntarismos, atentos a los signos de los tiempos y a la permanente llamada de Dios a captar y dilatar la presencia del Reino, inclusive en este contexto nuevo y desconcertante. Es en este mundo desbocado, que produce perplejidades y reclama sentidos, donde hay que vivir de nuestra particular llamada.

Ya Pablo VI en la exhortación apostólica Evangelii nuntiandi habló de los cambios en la cultura y en las culturas, y en la necesidad de evangelizarlas. Después de sostener que la evangelización es la finalidad y tarea fundamental de la Iglesia, y aclarar en qué consiste, afirma a modo de resumen: «Posiblemente podríamos expresar todo esto diciendo: lo que importa es evangelizar... la cultura y las culturas del hombre en el sentido rico y amplio que tienen sus términos en la Gaudium et spes, tomando siempre como punto de partida a la persona y teniendo siempre presentes las relaciones de las personas entre sí y con Dios» (EN 20).

Constatamos que tenemos dificultades para la transmisión de la fe. Estos cambios culturales, cambio de época, la postmodernidad líquida, y grupos humanos geolocalizados a la vez que deslocalizados (por las constantes migraciones), nos ponen delante de tiempos nuevos, de una nueva cultura y nuevas culturas. 
En este contexto, el papa Juan Pablo II urgió en 1992 a una nueva evangelización. Benedicto XVI convocó un Sínodo sobre la Nueva evangelización para la transmisión de la fe cristiana, y el papa Francisco nos regaló la exhortación Evangelii gaudium como hoja de ruta en este camino.

En todos los casos se constata la urgencia de nuestro tiempo de renovar la trasmisión de la fe cristiana, sea en las familias, parroquias o distinto tipo de comunidades, llamadas a comunicar la fe a las nuevas generaciones.

Hay dificultades culturales que a veces pueden desanimarnos o desalentarnos en nuestro quehacer evangelizador, pero si Dios nos ha considerado dignos de vivir en este tiempo es que tenemos la gracia para afrontarlo. No podemos rehuir a esta llamada.

¿Cómo renovamos el anuncio del Evangelio, para que sea nuevo en su ardor, en sus métodos, en su expresión? ${ }^{2}$

El papa Francisco lo ha definido con una imagen: «Iglesia en salida». Una Iglesia que no se contenta con conservar lo que tiene, sino que con audacia y esperanza se lanza por los caminos del Espíritu hacia las periferias existenciales de nuestro mundo. Hay que dejar de lado los temores paralizantes y los miedos que nos roban la esperanza.

Para ello necesitamos memoria, recordar lo que el Señor ha realizado en nuestra historia tanto personal como comunitaria; coraje, para afrontar los tiempos nuevos con la esperanza que viene del evangelio, y audacia, para explorar nuevos horizontes y lanzarnos sin miedo a la misión que se nos ha encomendado.

Sin una evangelización que transforme al hombre de hoy no habrá vocaciones duraderas.

Es en este contexto donde podemos hablar de cultura vocacional hoy.

\section{ElEMENTOS CONSTITUTIVOS DE LA CULTURA VOCACIONAL}

Una cultura vocacional es un ambiente que favorece que cada persona se comprenda a sí misma en función de una misión confiada por Dios para la extensión del Reino. Este ambiente está impregnado por valores, ideales, concepciones de la vida, convicciones de fe y expresiones pastorales que proporcionan que las personas de descentren de sí mismas, que miren más allá de sus propios proyectos, que se pongan a la escucha y al servicio de

2. «El punto de partida del discernimiento es el conocimiento de la realidad en la que vivimos. Con un conocimiento científico o profético de la realidad, intentamos descubrir ahí cuáles son las fuerzas que construyen y destruyen la vida humana. Sabiendo que Dios no está con los brazos cruzados, nos preguntamos: ¿Qué está haciendo Dios de nuevo en nuestra historia? ¿Qué movimientos experimento dentro de mí al mirar esta realidad, desde los ojos de Dios? ¿Cuál es la colaboración justa y precisa que Dios me ofrece vivir como gracia suya en este momento? (B. González Buelta, Orar en un mundo roto, 15). 
una misión que las trasciende y les ha sido confiada por Dios mismo para la transformación del mundo. Una cultura vocacional es aquella atmósfera donde se valora y se defiende la fidelidad a la propia vocación, porque ella ha sido recibida de Dios, porque es parte de la dignidad del ser humano y porque de ella depende la creación de un mundo nuevo.

El crear esa cultura puede ser hoy uno de los servicios más urgentes que hemos de prestar al Dueño de la mies, que nos llama a colaborar con Él, y según su modo, en la salvación del mundo. No es posible para cada uno de nosotros gestar por sí solo una cultura tal, pero sí el inspirar los diversos frentes educativos con este objetivo. Por esta razón, creemos que todo lo que favorezca o debilite una «cultura vocacional» es hoy apostólicamente decisivo y atañe, directa o indirectamente, a la pastoral vocacional y a la pastoral de toda la Iglesia.

Como afirma Amedeo Cencini: "La vida es don totalmente gratuito y no existe otro modo de vivir digno del hombre fuera de la perspectiva del don de sí mismo... La vocación nace del amor y lleva al amor, porque el hombre no puede vivir sin amor. Esta cultura de la vocación constituye el fundamento de la cultura de la vida nueva, que es vida de agradecimiento y gratuidad, de confianza y responsabilidad; en el fondo, es cultura del deseo de Dios» ${ }^{3}$.

Ya la exhortación postsinodal Pastores dabo vobis nos decía: «La Iglesia no sólo contiene en sí todas las vocaciones que Dios le otorga en su camino de salvación, sino que ella misma se configura como misterio de vocación, reflejo luminoso y vivo del misterio de la Santísima Trinidad. En realidad la Iglesia, 'pueblo congregado por la unidad del Padre, del Hijo y del Espíritu Santo, lleva en sí el misterio del Padre que, sin ser llamado ni enviado por nadie' (Rom 11, 33-35), llama a todos para santificar su nombre y cumplir su voluntad; ella custodia dentro de sí el misterio del Hijo, llamado por el Padre y enviado para anunciar a todos el Reino de Dios, y que llama a todos a su seguimiento; y es depositaria del misterio del Espíritu Santo que consagra para la misión a los que el Padre llama mediante su Hijo Jesucristo» (PDV 35).

La cultura vocacional debe abarcar cada vez más la conciencia eclesial, ir del conocimiento de lo particular o de la comunidad a la convicción universal de no poder construir ningún futuro sobre un modelo de hombre sin vocación.

Hoy las nuevas generaciones nos presentan apremiantes interrogantes sobre el sentido de la vida, confirmando que nada ni nadie puede ahogar en el hombre esta búsqueda y el deseo de encontrar y encontrarse con la Verdad. Este es el campo en el que se plantea la búsqueda de la vocación.

Como lo ha expresado el papa Francisco en su exhortación apostólica Evangelii gaudium: «Aunque no siempre es fácil abordar a los jóvenes, se

\section{A. Cencini, No cuentan los números, 56.}


creció en dos aspectos: la conciencia de que toda la comunidad los evangeliza y educa, y la urgencia de que ellos tengan un protagonismo mayor. Cabe reconocer que, en el contexto actual de crisis del compromiso y de los lazos comunitarios, son muchos los jóvenes que se solidarizan ante los males del mundo y se embarcan en diversas formas de militancia y voluntariado. Algunos participan en la vida de la Iglesia, integran grupos de servicio y diversas iniciativas misioneras en sus propias diócesis o en otros lugares. ¡Qué bueno es que los jóvenes sean 'callejeros de la fe', felices de llevar a Jesucristo a cada esquina, a cada plaza, a cada rincón de la tierra!» (EG 86).

Sabemos que los jóvenes de hoy tienen en su bolsillo la llave para abrir la evangelización a las nuevas generaciones. Por eso no podemos obviar o desatender sus búsquedas más hondas.

Muchas veces, en nuestras Iglesias particulares son claros los objetivos, así como las estrategias de fondo, pero quedan un poco difusos los pasos que dar para suscitar en nuestros jóvenes la disponibilidad vocacional; y esto porque, todavía hoy, resulta débil una cierta planificación educativa, dentro y fuera de la Iglesia, la planificación que debería ofrecer después, junto a la precisión del objetivo que alcanzar, los caminos pedagógicos que recorrer para conseguirlo.

La crisis vocacional es, ciertamente, también crisis de la propuesta pedagógica y del camino educativo. No podemos despreciar la cultura juvenil de hoy si queremos evangelizar y generar esta cultura vocacional.

Entendemos, pues, por cultura vocacional un dinamismo que se da en lo cognitivo, en lo afectivo y en la práctica. A esto le llamamos mentalidad, sensibilidad y praxis.

La mentalidad es la teología de la vocación. En estos tiempos de crisis y sequía vocacional en tantas Iglesias particulares se ha desarrollado, sin embargo, una abundante teología de la vocación o de las vocaciones.

Dios nos ha llamado a la existencia, a la fe, al seguimiento de su Hijo y a una especial configuración con su misterio. Por eso es el Eterno llamante, que no se cansa de salir a distintas horas del día para buscar obreros para su viña.

Es el Dios creador que nos crea por amor, nos dona la vida y a la vez nos llama a colaborar en su proyecto de salvación para la humanidad. Misterio que se nos ha revelado en Cristo, resplandor de la gloria del Padre, y que nos convoca a compartir su misión.

La sensibilidad es la apropiación de esta visión de Dios, que se hace espiritualidad, relación con Dios y con los hermanos.

La praxis es cuando el llamado se convierte en llamante y es capaz de ser eco para los demás de la llamada de Dios. En este sentido, como afirma el P. Cencini, la crisis no es de llamados (Dios siempre sigue llamando), sino de llamantes. ¿Cómo nos hacemos eco de esta llamada del Eterno para que 
otros puedan escuchar su voz y se sientan animados a responder con todo su corazón, con todas sus fuerzas y con todo su espíritu? Es la pedagogía para transformar la realidad desde la mentalidad y la sensibilidad.

Por consiguiente, promover la cultura vocacional no es sólo informar o hablar sobre la vocación, sino educar a todos los jóvenes para que puedan descubrir su vida misma como vocación. Es fomentar actitudes como la entrega de la vida, la confianza y apertura a Dios y a los otros; o despertar la inquietud por acoger el misterio, dejarse amar, sentir el gozo de la elección. Incluye el activar la capacidad de asombrarse, de apreciar la belleza, de vislumbrar la sed de infinito que late en el corazón humano. La cultura de la vocación aporta una nueva antropología que permita superar una visión empequeñecida del hombre. Valora el ser por encima de los quehaceres y coloca a cada persona ante Dios para que le pregunte con apertura de corazón: ¿Qué quieres de mi vida? Cuando esto ocurre, se dan respuestas vocacionales para el ministerio ordenado, la vida consagrada, para el matrimonio cristiano y el compromiso laical entendidos como auténtica vocación.

\section{HACIA UNA CULTURA VOCACIONAL}

Muchas voces repiten en la Iglesia que la verdadera urgencia de hoy es seguir proponiendo la cultura vocacional. Este es el primer objetivo de la pastoral vocacional, o más bien de la pastoral en general. Ahí deben centrarse todos los esfuerzos.

No se debe olvidar que ninguna vocación nace por sí misma o vive por sí misma. La vocación surge del corazón de Dios y brota en la tierra buena del pueblo fiel, en la experiencia del amor fraterno.

Como afirma Pastores dabo vobis: "La Iglesia, que por propia naturaleza es 'vocación', es generadora y educadora de vocaciones. Lo es en su ser de 'sacramento', en cuanto 'signo' e 'instrumento' en el que resuena y se cumple la vocación de todo cristiano; y lo es en su actuar, o sea, en el desarrollo de su ministerio de anuncio de la Palabra, de celebración de los sacramentos y de servicio y testimonio de la caridad» (PDV 45).

Hoy contamos con una buena orientación de la pedagogía vocacional. Toda ella se afirma sobre dos ejes: la siembra vocacional y el acompañamiento. Entre ambos ejes hay un nexo que los une: la propuesta vocacional. Tal propuesta es el objetivo de la siembra y, a su vez, el punto de partida del acompañamiento. Por tanto, fijamos esta pedagogía en tres momentos: siembra, propuesta y acompañamiento. Este último, a su vez, promueve las tareas de educar, formar y discernir las vocaciones.

Se ha pasado de una pastoral vocacional de reclutamiento a una de la espera (esperar a que surjan vocaciones). Hoy debemos pasar a la pastoral de la propuesta vocacional, del inmenso don de la vocación. 
Ofrecemos algunas pistas extraídas de lo dicho. Pretenden ofrecer sugerencias prácticas para que la animación vocacional de nuestras Iglesias particulares llegue a incidir de hecho en la creación de una cultura vocacional que fortalezca y difunda la teología, la sensibilidad y la pedagogía vocacionales a las que hemos aludido.

- Iniciar esa cultura vocacional en nuestros propios espacios, dirigiendo la atención hacia nosotros mismos, hacia cada uno de los que componemos nuestras comunidades eclesiales y nuestras estructuras pastorales. Necesitamos unas acciones permanentes de sensibilización que incidan sobre nuestras comunidades y sus responsables y coordinadores. Aquí tiene un lugar especial el Centro nacional de pastoral vocacional, como dinamizador y animador de los centros diocesanos, promoviendo la formación permanente de los agentes pastorales, generando comunión en el pensar y el actuar.

-Fortalecer la animación vocacional de la comunidad local. Esa es clave para la creación de una nueva cultura vocacional. Las estructuras de animación vocacional diocesanas suelen estar bien atendidas. Falta muchas veces fortalecer, dar estabilidad y definir las funciones concretas de los animadores vocacionales y los equipos de cada comunidad local. En ocasiones, estos se convierten en figuras meramente virtuales, normalmente sin apoyos y sin influencia en las comunidades y en la pastoral que en ella se desarrolla.

-Suscitar y formar animadores vocacionales idóneos que conformen Equipos locales de pastoral vocacional en misión compartida. A ello deben ser dirigidos nuestros mejores esfuerzos. Su tarea se inserta en los propios centros pastorales, evitando las duplicidades o el paro laboral vocacional. Sin ellos y sin una adecuada formación para esa tarea específica resultaría imposible dinamizar la creación de la cultura vocacional. Es importante que el animador vocacional sepa interpretar correctamente su identidad y su función: la del sembrador, la del acompañante, la del educador, la del formador vocacional, la de aquel que está llamado también a discernir, sin descuidar ninguna de estas funciones, ni crear confusión entre la una y la otra. Que sepa leer y ayudar a clarificar las motivaciones vocacionales del joven. «Acompañar, significa estar presente donde el joven vive su vida, donde él va buscando el sentido de la vida, donde al final se arriesga a experimentar frustración o donde la vida parece rechazarlo. En estos momentos la presencia de un hermano mayor es particularmente valiosa y podría significar el principio de un itinerario vocacional $»^{4}$.

En este sentido, es importante que el acompañante vocacional ayude al joven a releer su historia personal y familiar, a reconocer sus heridas profundas, revisar sus motivaciones y llevar todo esto al encuentro con Dios.

4. Ibid., 45. 
En estos días hemos visto el ejemplo de Moisés: abandonado en el río al nacer, criado por una familia que no era la suya, cuando quiere reencontrarse con los suyos se pone violento y termina lejos. Podría leer su historia como una vida desgraciada, sin un sentido profundo. O desde Dios, leer su vida como la de un hombre salvado por el Señor, que en el desierto de su vida le manifiesta que su llama sigue ardiendo, y por lo tanto lo hace capaz de ser instrumento de salvación para otros.

Esta relectura de la propia historia debe realizarse en el tiempo del discernimiento vocacional, pero debe continuar en las primeras etapas de la formación, como camino de discipulado.

El acompañante vocacional tampoco puede forzar procesos o decisiones. A veces se pueden ver en un joven condiciones para una vocación presbiteral o consagrada, pero él no siente la llamada o todavía no la reconoce. No se puede condicionar la conciencia.

Denunciar los abusos que impiden la cultura vocacional y provocan escándalo: mantener apatías e inhibiciones; impedir la promoción de otros carismas y ministerios eclesiales; menospreciar el trabajo vocacional que se realiza, retirar el apoyo o la continuidad de los proyectos vocacionales, ser negligentes ante la urgencia de suscitar y formar a los animadores vocacionales. También el no secundar sistemáticamente las orientaciones, diocesanas o congregacionales, que se nos han dado.

Sembrar el kerigma vocacional por todas partes, la Buen Noticia de la Vocación.

Esa paciente y continuada labor debe hacerse presente en todos los ámbitos (liturgia, catequesis, oración, acción caritativa, testimonio, economía...) y debe dirigirse a todos: a los integrantes de la comunidad cristiana y a los destinatarios de su misión. Incluimos entre los primeros a los responsables de nuestros centros pastorales y a sus colaboradores.

\section{CONCLUSIÓN}

La cultura vocacional no puede ser un añadido a la pastoral orgánica de las Iglesias particulares, sino que tiene que impregnar toda la vida apostólica.

Un punto importante aquí son los itinerarios formativos reales que se llevan adelante en los seminarios y casas de formación. A veces la sequía vocacional lleva a bajar bastante los niveles de exigencias para el ingreso, o para los cambios de etapa en la formación. Tenemos que tener presente que por cada uno que no debería estar, muchas veces hay dos o tres buenos candidatos que no quieren ingresar. El antitestimonio vocacional, o una propuesta light, lleva a que los jóvenes no quieran arriesgarse.

Hay que «vocacionalizar» las pastorales. Tres «mediaciones» nos ayudan a que esto sea realidad: 
a) Mediación eclesial. La animación vocacional no puede ser autónoma, ha de moverse en los espacios normales de la pastoral y de sus dimensiones: liturgia (oración personal y comunitaria), koinonía (expresión de la fraternidad de los miembros de la comunidad), diakonía (servicio a quien lo necesita) y martiría (testimonio del Evangelio). Cada vocación nace en la Iglesia; es mediación durante el despertar, discernir, cultivar (formación inicial) y acompañar (formación permanente).

b) Mediación pedagógica. Cuando las anteriores dimensiones están presentes en una comunidad, cada persona se plantea «normalmente» su vocación. Cada dimensión ayuda a madurar. La comunidad se transforma en mediación pedagógica.

c) Mediación psicológica. La objetividad precede a la subjetividad. El joven ha de descubrirse a sí mismo y lo que está llamado a ser. Primero, cada bautizado ha de hacer en su comunidad lo que se le exige a todos (crecer en la fe, comprometerse, participar, etc.), luego lo que es personal-vocacional. Ha de hacer lo que Dios pide a todos si quiere descubrir lo que Dios le pide a él. Ha de vivir lo que es "objetivo» y después asumir su modo propio de crecer. De esta forma, la Iglesia es «más madre» ${ }^{5}$.

Tenemos por delante una hermosa misión, la pastoral vocacional como cultura vocacional tiene más futuro que pasado, y se hace invitación para nosotros lo que afirma Cervantes en Don Quijote: «Soñar el sueño imposible, luchar contra el enemigo imposible, correr donde valientes no se atrevieron, alcanzar la estrella inalcanzable. Ese es nuestro destino».

5. Ibid., 49. 